\title{
Self-aggregation of hydrophobically modified dextrin and their interaction with surfactant
}

\author{
Guangyue Bai ${ }^{a}$, Catarina Gonçalves ${ }^{b}$, \\ Francisco M. Gama ${ }^{\mathrm{b}}$, Margarida Bastos ${ }^{\mathrm{a}, *}$ \\ ${ }^{a} C I Q(U P)$, Department of Chemistry, Faculty of Sciences, University of Porto, \\ R. Campo Alegre, 687, P-4169-007 Porto, Portugal \\ ${ }^{\mathrm{b}}$ IBB - Institute for Biotechnology and Bioengineering, Centre for Biological Engineering, \\ Universidade do Minho, Campus de Gualtar 4710-057, Braga, Portugal
}

Received 3 August 2007; received in revised form 4 October 2007; accepted 9 November 2007

Available online 19 November 2007

\begin{abstract}
A series of newly hydrophobically modified polymers $\left(\operatorname{dexC}_{16}\right)$ with different degrees of substitution $\left(\mathrm{DS}_{\mathrm{C} 16}\right)$ have been synthesized. They can self-assemble to form micelle-like aggregates through association of the hydrophobic alkyl chains in aqueous solution. The self-aggregation processes, i.e. the critical micelle concentrations (cmc's) of the polymers were characterized by steady-state fluorescence. Further, the interaction between these dexC $\mathrm{C}_{16}$ polymers and ionic surfactants (SOS, SDS and DTAC) was investigated by isothermal titration calorimetry (ITC). For the studied mixed systems some important parameters can be derived from calorimetric titration curves, such as interaction enthalpies, critical concentrations and enthalpies of aggregation. The critical concentrations and the aggregation behaviour for the dexC $16 / \mathrm{SDS}$ system were confirmed by fluorescence measurements. The effects of hydrophobic side group concentrations on the interaction were evaluated in detail. Importantly, we show that the aggregation behaviour of the mixed systems depends on the molar ratio of surfactant to hydrophobic side group $\left(R=n_{\mathrm{s}} / n_{\text {side group }}\right)$. (C) 2007 Elsevier B.V. All rights reserved.
\end{abstract}

Keywords: Hydrophobically modified dextrin; Polymer-surfactant interaction; Self-aggregation; Calorimetry; ITC; Fluorescence

\section{Introduction}

Hydrophobically modified polymers (HMP) have attracted much attention due to their hydrophilicity, biodegradability, and antibacterial properties. As such, they are being considered as a new class of amphiphilic materials [1-9]. They have a strong tendency to self-associate and/or to associate with surfactants, forming spontaneously hydrophobic cores which exhibit a great potential in drug/gene delivery research and in other biomedical applications [10-18].

It is well known that the intra- or inter-molecular associations of HMP mainly result from hydrophobic interactions within the same polymer chains or between different chains. The association between polymer and surfactant often results from a relatively weak dipolar interaction between polymer seg-

\footnotetext{
* Corresponding author. Tel.: +35122 402511; fax: +35122402659.

E-mail address: mbastos@fc.up.pt (M. Bastos).
}

ments and surfactant head groups, which must in general be governed by a subtle balance of hydrophilic, hydrophobic, and ionic interactions [19]. Both the mechanism of the association and the strength of the interaction depend to a great extent on the molecular architecture and the characteristics of the polymer, i.e., the degree of substitution, the chain conformation as well as the hydrophobicity of polymer backbone and pendant groups. It is of particular importance to understand the effect of these factors on polymer-surfactant interactions so as to be able to design new polymers with the desired properties. Further, the more detailed thermodynamic information about the interactions the better should be our understanding of its mechanism. Calorimetric measurements have been very successfully used to characterize both the critical aggregation concentration and the energetics of various polymer-surfactant interactions, as well as to identify factors and driving forces that govern the interactions in such systems [19-27].

A series of new hydrophobically modified polymers $\left(\operatorname{dexC}_{16}\right)$ have been synthesized [28]. Briefly, a hydrophilic dextrin back- 


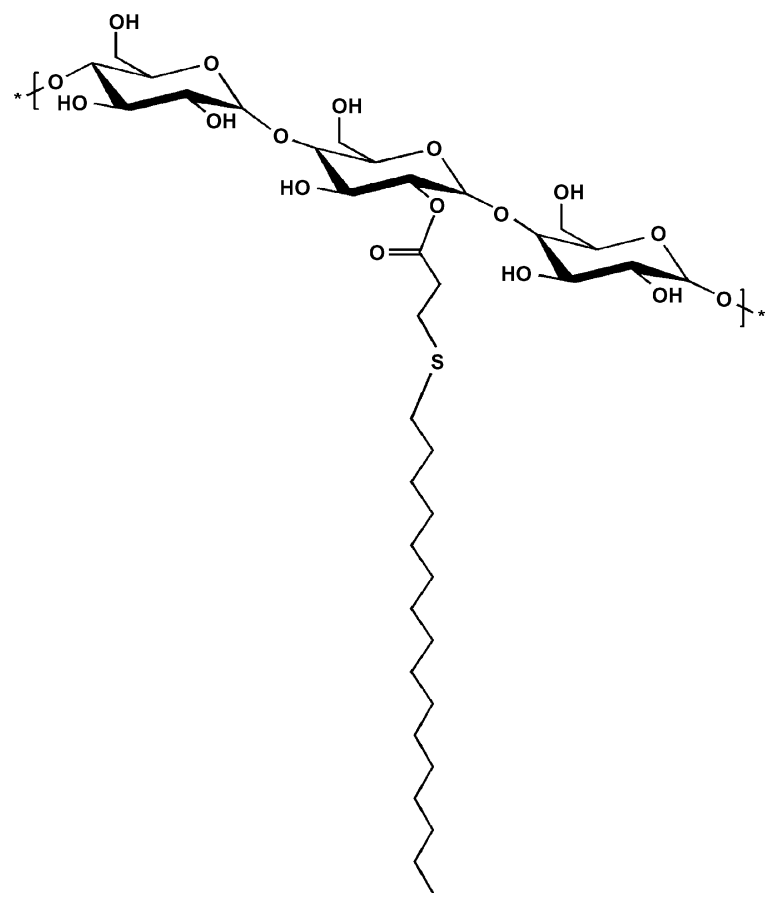

Fig. 1. Chemical structure of the studied polymers $\left(\operatorname{dex} C_{16}\right)$ obtained by hydrophobic modification of dextrin.

bone has been grafted with acrylate groups (VA), which were subsequently substituted with hydrophobic 1-hexadecanethiol $\left(\mathrm{C}_{16}\right)$. Their chemical structure is shown in Fig. 1. The pendant groups are randomly distributed along the dextrin backbone, and polymers with different degrees of substitution $\left(\mathrm{DS}_{\mathrm{C} 16}\right)$ were prepared. They may be looked upon as a "poly-surfactant" connected by hydrophilic spacers at the level of head groups. Indeed they exhibit self-aggregation behaviour, similar to surfactants in aqueous solution. For one of the polymers, the interesting self-aggregation properties were confirmed by Dynamic Light Scattering, Fluorescence and Atomic Force Microscopy. It was shown that the hydrophobic side chains can self-assemble to form micelle-like aggregates of nanosize dimensions at very low concentration [28].

In the present work the self-assembling in aqueous solution of various members of this family, with different $\mathrm{DS}_{\mathrm{C} 16}$, was studied by steady-state fluorescence. The polymer-surfactant association was assessed by isothermal titration calorimetry
(ITC) and fluorescence. From fluorescence results, critical concentrations were estimated for the pure polymers and for their mixtures with surfactants. From the ITC results we derived the interaction enthalpies, critical concentrations and enthalpies of aggregation.

The association processes of polymer-surfactant can be tentatively inferred from the calorimetric titration curves. Further the dependence of the aggregation behaviour of mixed systems on the molar ratio of surfactant to hydrophobic side group $\left(R=n_{\mathrm{S}} / n_{\text {side group }}\right)$ is discussed

\section{Experimental}

\subsection{Materials}

Synthesis of the studied polymers, dextrin-VA-SC 16 (dexC $\mathrm{C}_{16}$, Fig. 1) has been done according to previously described methods [28]. Briefly, the dextrin-VA was first prepared by grafting acrylate groups to a dextrin sample (Koldex 60, Tate \& Lyle, $M_{\mathrm{w}} 45700 \mathrm{Da}$ (determined by gel permeation chromatography)), with $20 \%$ degree of substitution, i.e. 20 acrylate groups per 100 dextrin glucopyranoside residues $(\mathrm{DS}(\mathrm{VA})=20 \%)$. Then the obtained dextrin-VA and 1-hexadecanethiol (SIGMA, 92\%) were dissolved in dimethylsulfoxide (Applichem, p.A.). The reaction between the thiol moiety and the acrylate group of dextrin-VA is a conjugate addition, with thiol acting as a nucleophile. Different molar percentages of 1-hexadecanethiol, $x \%$ $(20,40,60,80,100 \%$ relatively to VA) were added to the reaction mixture, so that different degrees of grafting were obtained. The ${ }^{1} \mathrm{H}$ NMR spectra of $\operatorname{dex}_{16}$ in deuterated water was used to determine the degree of substitution actually obtained in each case $\left(\mathrm{DS}_{\mathrm{C} 16}\right.$, amount of alkyl chains per 100 dextrin glucopyranoside residues) [28]. The main characteristics of the studied polymers are summarized in Table 1.

The surfactants, sodium octyl sulfate (SOS) (MERCK, 99\%), sodium dodecyl sulfate (SDS) (SIGMA, 99\%) and dodecyltrimethylammonium chloride (DTAC) (TCI, >98\%) were used without further purification. All solutions were prepared by volume, using water produced by a Milli-Q filtration system. Surfactant concentration is reported in $\mathrm{mol} \mathrm{dm}^{-3}$ and polymer concentration in $\mathrm{g} \mathrm{dL}^{-1}$. The polymer aqueous solutions were prepared at room temperature and then warmed at $50^{\circ} \mathrm{C}$ in an ultrasonic bath (Bandelin RK $100 \mathrm{H}$ ) for $20 \mathrm{~min}$. It is worth not-

Table 1

Characteristics of the studied $\operatorname{dex} \mathrm{C}_{16}$ polymers

\begin{tabular}{|c|c|c|c|c|c|}
\hline Samples & $\operatorname{dex} C_{16}-1 \%$ & $\operatorname{dex} C_{16}-3 \%$ & $\operatorname{dex} C_{16}-5 \%$ & $\operatorname{dex} C_{16}-7 \%$ & $\operatorname{dex} C_{16}-10 \%$ \\
\hline $\mathrm{DS}(\mathrm{VA})^{\mathrm{a}}(\%)$ & 20 & 20 & 20 & 20 & 20 \\
\hline$x \%^{\mathrm{b}}$ & 20 & 40 & 60 & 80 & 100 \\
\hline $\mathrm{DS}_{\mathrm{C} 16}{ }^{\mathrm{c}}(\%)$ & 1 & 3 & 5 & 7 & 10 \\
\hline$M_{\mathrm{W}}^{\mathrm{d}}$ & 51961 & 53492 & 55022 & 56552 & 58848 \\
\hline$N^{\mathrm{e}}$ & 3 & 8.9 & 14.8 & 20.7 & 29.6 \\
\hline
\end{tabular}

a The degree of substitution for VA, i.e. 20 acrylate groups per 100 dextrin glucopyranoside residues.

b Different molar percentages of 1-hexadecanethiol relatively to VA.

c The degree of substitution means the amount of alkyl chains per 100 dextrin glucopyranoside residues, and determined by ${ }^{1} \mathrm{H}$ NMR.

d Molecular weight calculated by adding the weight of pendant groups to the molecular weight of unmodified dextrin.

e The number of hydrophobic modified side chains for per mol polymer chain. 
ing that the solubility depends on the degree of substitution, as increasing the degree of substitution reduces solubility.

\subsection{Fluorescence measurement}

Steady-state fluorescence is commonly used to determine the onset of aggregation of amphiphilic molecules, the critical micellization concentration ( $\mathrm{cmc}$ ). Pyrene (Py) is the most used fluorescent probe, and its fluorescent properties change when it is transferred from an aqueous environment to the hydrophobic microenvironment of the aggregates. Fluorescence measurements were performed on a VARIAN Cary Eclipse fluorescence spectrofluorometer with a quartz cell. The spectra were obtained at an excitation wavelength of $337 \mathrm{~nm}$, and recording the emission over the range $350-500 \mathrm{~nm}$, at a scan rate of $120 \mathrm{~nm} \mathrm{~min}^{-1}$. The slit width was set at $20 \mathrm{~nm}$ for the excitation and $2.5 \mathrm{~nm}$ for the emission. The fluorescent intensity, for each vibronic peak, was measured at the maximum of each peak.

\subsection{Isothermal titration calorimetry (ITC)}

The microcalorimeter unit used in this work consisted of a twin heat conduction calorimeter with $3 \mathrm{~mL}$ titration cell (ThermoMetric AB, Järfalla, Sweden), a water bath and its controller, built at Lund University, Sweden, and a71/2 digit HP nanovoltmeter connected to the calorimetric channel and to the computer. The calorimetric unit used in this work as well as the instrumental procedure has been described in detail in our previous work [29]. Briefly, the volume of polymer solution or water in the calorimetric vessel was $2.6 \mathrm{~cm}^{3}$. The calorimetric titration experiments consisted of a series of consecutive additions of (i) concentrated surfactant solution into water or polymer solutions; or (ii) mixed polymer/surfactant solution (with different ratios of SDS to polymer side chains) into water. The titrating solution was added to the vessel automatically, in aliquots of 1.7-8.3 $\mu \mathrm{L}$, from a modified gas-tight Hamilton syringe, through a thin stainless-steel capillary, until the desired range of concentration had been covered. A special Kel-F turbine, made at Lund University workshop (Sweden) was used throughout, as we have shown that it promotes very good mixing. All experiments were performed at $308.15 \pm 0.01 \mathrm{~K}$. The results reported are the average of three independent measurements.

\section{Results and discussion}

\subsection{Self-aggregation of dexC $C_{16}$ in aqueous solution}

Fluorescence measurements have been made on dex $\mathrm{C}_{16}$ polymers of different degrees of substitution, $\mathrm{DS}_{\mathrm{C} 16}$ (in mol\%). In the case of the emission spectra, the variation of the relative intensities of the first and third vibronic peaks $\left(I_{1} / I_{3}\right.$ or $\left.I_{3} / I_{1}\right)$ with amphiphile concentration is frequently used for obtaining the critical concentrations and for evaluating the aggregate's formation [30]. Fig. 2 shows the variation of the fluorescence intensity ratio $\left(I_{3} / I_{1}\right)$ with the polymer concentration, $C_{\text {polymer }}$ (Fig. 2a) and with the polymer hydrophobic side group concentration, $C_{\text {side group }}$ (Fig. 2b). The reason for using this second
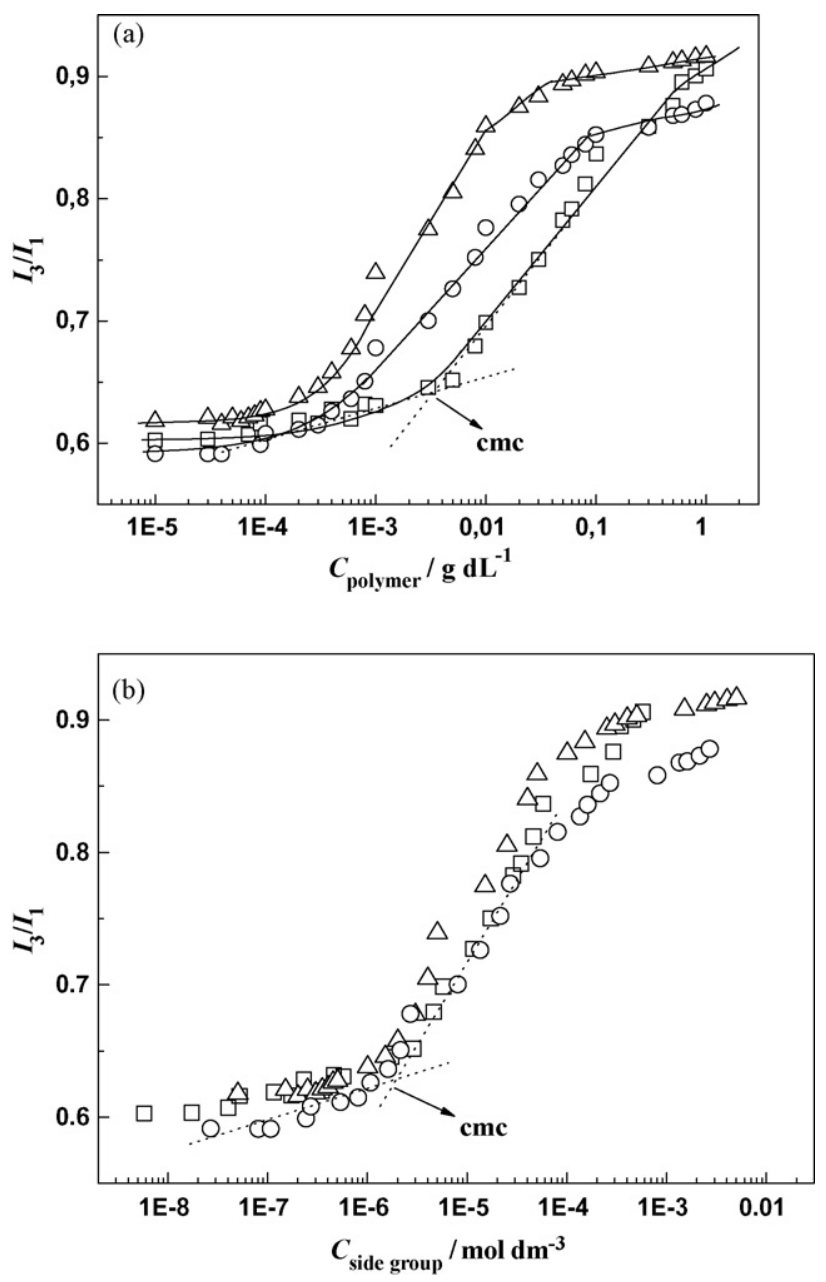

Fig. 2. Typical plots for fluorescence intensity ratio $I_{3} / I_{1}$ for polymers with different degrees of substitution, $\mathrm{DS}_{\mathrm{C} 16}$ (in mol\%): $(\square) \operatorname{dexC}_{16}-1 \%$; $(\bigcirc)$ $\operatorname{dexC}_{16}-5 \% ;(\triangle) \operatorname{dexC}_{16}-10 \%$. The values of $I_{3} / I_{1}$ are plotted as a function of (a) the polymer concentration (in $\mathrm{g} \mathrm{dL}^{-1}$ ); (b) hydrophobic side group concentration (in $\mathrm{mol} \mathrm{dm}^{-3}$ ).

concentration unit ( $\left.C_{\text {side group }}\right)$ will be explained bellow. The $I_{3} / I_{1}$ values show a significant increase at a certain polymer concentration (Fig. 2a), suggesting that an event takes place at this critical concentration, which must be the association between polymer side chains (intra- or intermolecular association), forming micelle-like aggregates, as the change in $I_{3} / I_{1}$ values indicate a decrease in polarity of the environment of the fluorescent probe, thus suggesting the formation of hydrophobic microdomains. Therefore this concentration corresponding to the onset of the fluorophore property's change $\left(I_{3} / I_{1}\right)$ is considered here to be the critical micelle concentration $(\mathrm{cmc})$ [28]. Its value was obtained at the crossing of the two linear segments before and after the onset of the fluorophore property's change, as shown in Fig. 2a. Interestingly, the obtained cmc values from the $I_{3} / I_{1}$ vs. $C_{\text {polymer }}$ curves (Fig. 2a) decrease with increasing $\mathrm{DS}_{\mathrm{C} 16}$, but if we obtain cmc from the $I_{3} / I_{1} v s$. $C_{\text {side group }}$ curves (Fig. 2b) the obtained cmc values are almost the same for different $\mathrm{DS}_{\mathrm{C} 16}$. These results are summarized in Table 2, where cmc values of the studied dex $\mathrm{C}_{16}$ polymers are expressed in both units. When expressed in $C_{\text {side group }}$ cmc appears at 
about the same concentration for all polymers studied, namely $\sim 2 \times 10^{-6} \mathrm{~mol} \mathrm{dm}^{-3}$. This is a very important result, as we have stressed before [31] — when working with hydrophobically modified polymers with different degrees of substitution, the results should be plotted or discussed as a function of concentration of hydrophobic side groups and not on polymer concentration. The fact that we obtain approximately the same cmc value in this scale for these studied polymers (with different $\mathrm{DS}_{\mathrm{C} 16}$ ) means that the type of aggregate and size are the same, as they appear at the same "concentration" of side chains. This situation has also been addressed by Piculell et al. [32] as they also suggest that the hydrophobic side groups rather than the polymer backbone should be considered to be the fundamental unit of the hydrophobically modified polymers, since the hydrophobes are responsible for the strong association phenomena observed.

Further, cmc's, when expressed as a function of side group concentration, are of the same order of magnitude as the $\mathrm{cmc}$ values of single chain non-ionic surfactants with the same number of carbon atoms on the alkyl chain (e.g., the $\mathrm{cmc}$ for $\mathrm{C}_{16} \mathrm{E}_{9}$ is $2.1 \times 10^{-6} \mathrm{~mol} \mathrm{dm}^{-3}$, for $\mathrm{C}_{16} \mathrm{E} 12$ is $2.3 \times 10^{-6} \mathrm{~mol} \mathrm{dm}^{-3}$ and for $\mathrm{C}_{16} \mathrm{E}_{21}$ is $3.9 \times 10^{-6} \mathrm{~mol} \mathrm{dm}^{-3}$ ) [33]. This comparison again stresses the importance of expressing the polymer concentration in hydrophobic side group concentration.

\subsection{Calorimetric study on interaction enthalpy}

Calorimetric titration measurements were performed at $308.15 \mathrm{~K}$ at two polymer concentrations $\left(C=0.13 \mathrm{~g} \mathrm{dL}^{-1}\right.$ and $\left.0.25 \mathrm{~g} \mathrm{dL}^{-1}\right)$. At these concentrations the polymer will be in micellar form at the beginning of the titration $(C>\mathrm{cmc}$, see Table 2). The calorimetric curves representing the variation of the observed enthalpies $\left(\Delta H_{\text {obs }}\right)$ with SDS concentration ( $\left.C_{\text {surfactant }}\right)$ are shown in Fig. 3, where (a) and (b) show the results of addition of concentrated SDS solution to dexC $\mathrm{C}_{16}-1 \%$ and dexC $\mathrm{C}_{16}-3 \%$ solutions, respectively. The corresponding dilution enthalpy curve of SDS into water is also included in the figures for comparison.

All curves present a similar pattern for the observed enthalpy change. The most obvious feature is that in the beginning of the titration (below $C_{\mathrm{SDS}}=3.0 \times 10^{-3} \mathrm{~mol} \mathrm{dm}^{-3}$ ), the $\Delta H_{\mathrm{obs}} v s$. $C_{\text {SDS }}$ curves deviate quite significantly from the dilution curve of SDS in water, showing a pronounced exothermic effect. As we have surfactant micelles in the syringe $(C(\mathrm{syr})>\mathrm{cmc})$ the observed enthalpy must be the net result of de-micellization (endothermic contribution) and monomer/polymer interaction when the surfactant concentration in the vessel is below its own cmc $\left(7.7 \times 10^{-3} \mathrm{~mol} \mathrm{dm}^{-3}\right.$, see Fig. 3a and Ref. [29]). The
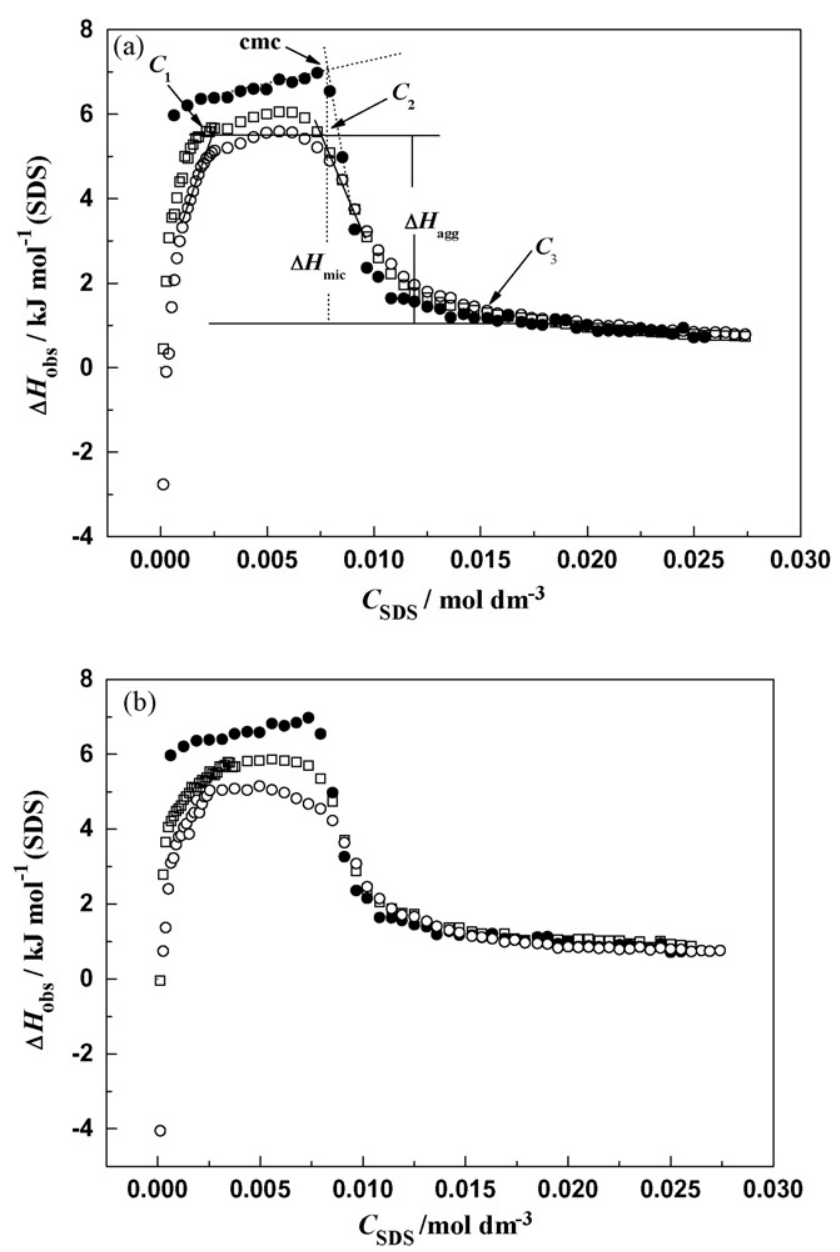

Fig. 3. Calorimetric titration curves for the dilution of concentrated SDS, $C=0.2 \mathrm{~mol} \mathrm{dm}^{-3}$ into water $(\bullet)$ and $\operatorname{dexC}_{16}$ solutions $\left(0.13 \mathrm{~g} \mathrm{dL}^{-1}(\square)\right.$ and $0.25 \mathrm{~g} \mathrm{dL}^{-1}(\bigcirc)$ ) at $308.15 \mathrm{~K}$. (a) $\mathrm{dexC}_{16}-1 \% / \mathrm{SDS}$; (b) dexC $\mathrm{C}_{16}-3 \% / \mathrm{SDS}$.

global equation could be written as:

$\frac{1}{n} \mathrm{~S}_{n}(\mathrm{mic})+\mathrm{P}(\mathrm{agg}) \rightarrow \mathrm{S}-\mathrm{P}($ complex $)$

Then we have to consider also the demicelization process, as referred to above, as depicted in Eq. (2):

$\frac{1}{n} \mathrm{~S}_{n}(\mathrm{mic})+\mathrm{aq} \rightarrow \mathrm{S}$ (monomer)

After demicelization, we have in the vessel the interaction between surfactant monomers $S$ (monomer) and polymer aggregates $\mathrm{P}$ (agg) to form a surfactant-polymer complex $\mathrm{S}-\mathrm{P}$, as written in the Eq. (3)

$\mathrm{S}($ monomer $)+\mathrm{P}($ agg $) \rightarrow \mathrm{S}-\mathrm{P}($ complex $)$

Table 2

Critical micelle concentrations ( $\mathrm{cmc}$ ) of the studied $\operatorname{dex}_{16}$ polymers expressed in different units

\begin{tabular}{llllll}
\hline Polymers & $\operatorname{dexC}_{16}-1 \%$ & $\operatorname{dexC}_{16}-3 \%$ & $\operatorname{dexC}_{16}-5 \%$ & $\operatorname{dexC}_{16}-7 \%$ & 0.60 \\
\hline $10^{3} \times c\left(\mathrm{~g} \mathrm{dL}^{-1}\right)$ & 3.0 & 1.0 & 0.80 & 0.40 \\
$10^{6} \times c^{\prime}\left(\mathrm{mol}_{\text {side group }} \mathrm{dm}^{-3}\right)$ & 1.7 & 1.7 & 2.2 & 2.2 & 2.0 \\
\hline
\end{tabular}

Note: the first row represents the concentration, $c$, in gram of polymer per solution volume (in $\mathrm{dL}$ ); in the second row this was transformed into $c^{\prime}$, in mol of hydrophobic side group per solution volume $\left(\mathrm{dm}^{3}\right)$ 
Table 3

Interaction enthalpies $\left(\Delta H_{\text {int }}\right)$ and enthalpies of aggregation $\left(\Delta H_{\text {agg }}\right)$ for $\operatorname{dexC}_{16} /$ surfactant systems at $308.15 \mathrm{~K}$

\begin{tabular}{|c|c|c|c|c|}
\hline Systems & $\begin{array}{l}C_{\text {polymer }} \\
\left(\mathrm{g} \mathrm{dL}^{-1}\right)\end{array}$ & $\begin{array}{l}10^{3} \times C_{\text {side group }}{ }^{\mathrm{a}} \\
\left(\mathrm{mol} \mathrm{dm}^{-3}\right)\end{array}$ & $\begin{array}{l}\Delta H_{\mathrm{int}}^{\mathrm{b}, \mathrm{c}} \\
\left(\mathrm{kJ} \mathrm{mol}^{-1}\right)\end{array}$ & $\begin{array}{l}\Delta H_{\mathrm{agg}}{ }^{\mathrm{c}} \\
\left(\mathrm{kJ} \mathrm{mol}^{-1}\right)\end{array}$ \\
\hline \multirow[t]{2}{*}{$\mathrm{SDS}+\operatorname{dex} \mathrm{C}_{16}-1 \%$} & 0.13 & 0.070 & -5.5 & -4.5 \\
\hline & 0.25 & 0.14 & -8.8 & -4.0 \\
\hline \multirow[t]{2}{*}{$\mathrm{SDS}+\operatorname{dex} \mathrm{C}_{16}-3 \%$} & 0.13 & 0.21 & -6.0 & -4.5 \\
\hline & 0.25 & 0.42 & -10.1 & -3.9 \\
\hline \multirow[t]{2}{*}{$\mathrm{DTAC}+\operatorname{dex} \mathrm{C}_{16}-3 \%$} & 0.13 & 0.21 & -0.5 & -1.3 \\
\hline & 0.25 & 0.42 & -1.3 & -1.1 \\
\hline
\end{tabular}

a The concentrations are expressed in concentration of polymer hydrophobic side group $\left(\mathrm{mol} \mathrm{dm}^{-3}\right)$.

b Calculation based on the first injection (at $C_{\mathrm{SDS}}=0.1 \times 10^{-3} \mathrm{~mol} \mathrm{dm}^{-3}$ for $\operatorname{dexC}_{16} / \mathrm{SDS}$ and at $C_{\mathrm{DTAC}}=0.4 \times 10^{-3} \mathrm{~mol} \mathrm{dm}^{-3}$ for $\left.\operatorname{dexC}_{16} / \mathrm{DTAC}\right)$.

c The estimated errors in enthalpies are less than $4 \%$.

Reaction (1) represents the total process, and is reflected in the measured enthalpy, $\Delta H_{\mathrm{obs}}(1)$, which includes the enthalpy of demicelization (reaction (2)) as well as the enthalpy of surfactant/polymer interaction. By subtracting Eq. (2) from Eq. (1) we obtain Eq. (3), and we can therefore calculate the enthalpy of surfactant/polymer interaction as:

$\Delta H_{\text {int }}=\Delta H_{\mathrm{obs}}(1)-\Delta H_{\mathrm{obs}}(2)$

With the above equation, the interaction enthalpies at the first injection are calculated for these studied systems $\left(C_{\mathrm{SDS}}=0.1 \times 10^{-3} \mathrm{~mol} \mathrm{dm}^{-3}\right)$. The values are given in Table 3 . It is found that increasing either the polymer concentration or the degree of substitution $\left(\mathrm{DS}_{\mathrm{C} 16}\right)$ results in an increase in the exothermic interaction enthalpy. Nevertheless these two factors affect the enthalpy to a different extent, as can be clearly seen if we calculate the ratios between the exothermic interaction enthalpies given in Table 3 . For the systems $\mathrm{SDS}+\operatorname{dex} \mathrm{C}_{16}-1 \%$ and $\mathrm{SDS}+\operatorname{dexC}_{16}-3 \%$, if we compare the effect of changing polymer concentration for the same $\mathrm{DS}_{\mathrm{C} 16}$, when the hydrophobic side group concentration doubles, the ratio between the exothermic enthalpies $\Delta H_{\text {int }}$ is $\sim 1$.6. If we compare the same polymer concentration but different degrees of substitution $\left(\mathrm{DS}_{\mathrm{C} 16}=1 \%\right.$ and $\left.3 \%\right)$, when the hydrophobic side group concentration increases three times, the ratio of enthalpies $\left(\Delta H_{\text {int }}\right)$ is only $\sim 1.1$. In an attempt to rationalize these differences, we would like to point out the following: (i) in both situation above (i.e., changing DS and keeping polymer concentration or the opposite) when the SDS concentration is very low, the added SDS micelles dissociate first into monomers, and then the SDS monomers are incorporated into the $\mathrm{Dex}_{16}$ aggregates, until the DexC $_{16}$ aggregates start to disintegrate and the rehydration of polymer backbone occurs [34-36]. (ii) When we have the same $\mathrm{DS}_{\mathrm{C} 16}$, the increase of hydrophobic side group concentration (from increase in polymer concentration) results in strengthening of the intermolecular interactions between different polymer chains, favouring the formation of loose cross-linking aggregates. As a result the addition of SDS leads easily to the surfactant-induced break-up of polymer aggregates and subsequent rehydration of polymer backbone. This reflects in a large exothermic enthalpy at low surfactant concentration. (iii) When we have different $\mathrm{DS}_{\mathrm{C} 16}$ with the same polymer concentration, the increase of total hydrophobic side group concentration as well as the density of hydrophobic side groups along the dextrin backbone results in strengthening of the intra-molecular interaction in the same polymer chains, which favours the formation of compact and stable aggregates. Compared with the former (ii), this might make surfactant-induced break-up of polymer aggregates difficult, and thus relative weaker re-hydration of polymer backbone will occur. These events could be the possible reason for the observed different relative increases in exothermic enthalpies in the two cases.

When SDS concentration reaches $C_{1}$ (see Fig. 3a), the insertion of SDS monomers into polymer aggregates and the surfactant-induced break-up of polymer aggregates lead to the formation of smaller DexC ${ }_{16} / \mathrm{SDS}$ mixed micelles, involving several alkyl chains from the surfactant and the polymer. At this point, the rehydration of the polymer backbone becomes weaker, and therefore the smaller exothermic interaction enthalpies reflect the hydrophobic interaction between the alkyl chains. Between $C_{1}$ and $C_{2}$ we have structural rearrangements giving rise to intermediate structures, such as the resulting mixed micelles that are formed upon increasing SDS concentration. The dissociation of the $\operatorname{dex}_{16}$ aggregates caused by SDS monomers proceeds as well as the formation of progressively SDS-rich mixed micelles. In this concentration range, the interaction enthalpies change slightly with increasing concentration SDS but the $\Delta H_{\text {int }}$ values depend on polymer concentration. When the polymer concentration increases, the relative number of pendant cetyl chains involved in mixed micelle aggregates also increases, and therefore the interaction enthalpy also changes. The mixed micelle formation explains the observed increase in polymer solubility upon surfactant addition.

When SDS concentration reaches $C_{2}$, the molar ratios of SDS to polymer side chain are very high (see Fig. 6a and the text later in Section 3.4). Therefore the continuous increase of SDS content in such mixed micelles eventually leads to a complete extending of the polymer chain, with the dexC16 monomers "decorated" with SDS micelles until saturation of the polymer with SDS occurs at $C_{3}=\sim 15 \times 10^{-3} \mathrm{~mol} \mathrm{dm}^{-3}$. After this concentration the added SDS micelles are only diluted, and free SDS micelles are stable.

For all studied systems, $C_{2}$ values are almost the same as the cmc of SDS in water and they are independent of the hydrophobic side group concentration. Therefore this concentration $C_{2}$ is considered as the surfactant aggregation concentration in the presence of polymer. The corresponding aggregation enthalpies $\left(\Delta H_{\mathrm{agg}}\right)$ can be obtained from the difference between the observed enthalpies at the two linear segments [19] as shown in Fig. 3a. These results are also summarized in Table 3. The exothermic $\Delta H_{\text {agg }}$ values are smaller than the $\Delta H_{\text {mic }}$ $\left(-5.4 \mathrm{~kJ} \mathrm{~mol}^{-1}\right)$ of SDS. The difference between $\Delta H_{\mathrm{agg}}$ and $\Delta H_{\text {mic }}$ (of pure SDS) indicates some interaction between monomeric SDS and polymer. Since the binding extent cannot be derived from our data, the enthalpies are referred here as usually to the total amount of added SDS. The agreement between the values of $C_{2}$ and the cmc of SDS in water together with the close similarity of the dilution curves for the mixed systems 


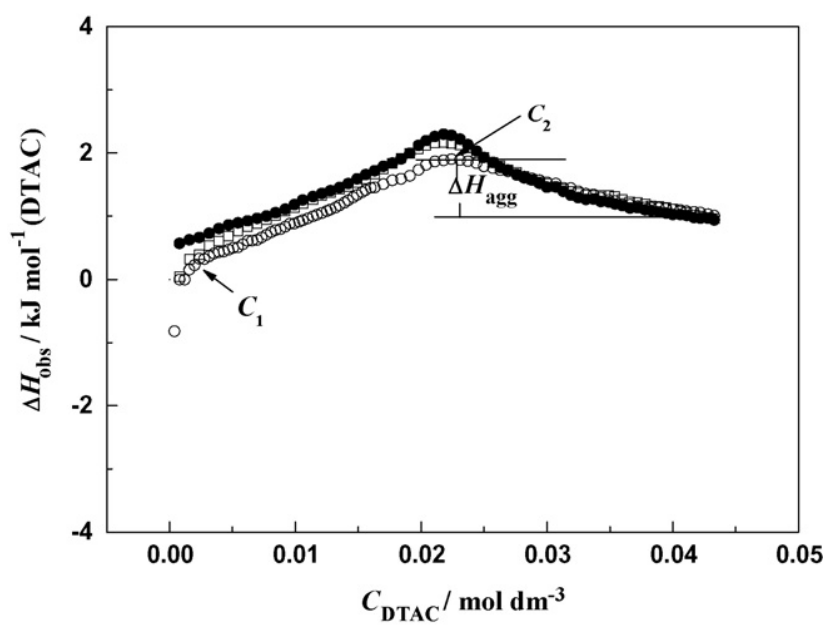

Fig. 4. Calorimetric titration curves for the dilution of concentrated DTAC $C=0.25 \mathrm{~mol} \mathrm{dm}^{-3}$ into water $(\bullet)$ and $\operatorname{dexC}_{16}-3 \%$ solution at $308.15 \mathrm{~K}$. The polymer concentration is $0.13 \mathrm{~g} \mathrm{dL}^{-1}(\square)$ and $0.25 \mathrm{~g} \mathrm{dL}^{-1}(\bigcirc)$.

and pure SDS may indicate that only a fairly small fraction of SDS interacts with the polymers. The values of $\Delta H_{\text {agg }}$ are negative for all studied systems, suggesting that the process is either enthalpy-driven or enthalpy- and entropy-driven, depending on the relative magnitude of the two thermodynamic properties.

Furthermore, a calorimetric titration curve for dexC $\mathrm{C}_{16}-3 \%$ $\left(0.13 \mathrm{~g} \mathrm{dL}^{-1}\right)$ with SOS (not shown) shows no difference from the SOS dilution curve in water, indicating that no interaction is detected when the alkyl chain length of surfactant is shorter. Indeed the alkyl chain length of the surfactant is one of key factors controlling the strength of the hydrophobic interaction.

On the other hand, if we compare now the results for polymer/SDS with the ones obtained for the interaction of the cationic surfactant DTAC with the same polymer, we see that for the mixed systems with DTAC the interaction also takes place at very low concentration of surfactant, i.e., $C_{1}$ is also below $3.0 \times 10^{-3} \mathrm{~mol} \mathrm{dm}^{-3}$ (Fig. 4), but the interaction enthalpies are larger with SDS. The values of $C_{2}$ for $\operatorname{dexC}_{16^{-}}$ $3 \% / \mathrm{DTAC}$ system show almost no change from pure DTAC $\mathrm{cmc}$ $\left(24.2 \times 10^{-3} \mathrm{~mol} \mathrm{dm}^{-3}\right)[31]$ and the changes in the calorimetric curves are relatively small. The corresponding enthalpies of surfactant aggregation in the presence of polymer $\left(\Delta H_{\mathrm{agg}}\right)$ are

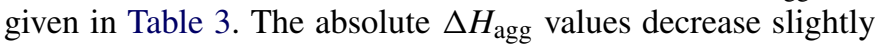
as the polymer concentration increases. This indicates that the anionic surfactant aggregation in the presence of polymer is to some extent different from the one with cationic surfactant. This result is similar to the one reported for PAM-C $\mathrm{C}_{10}(2 \%)$-AA/SDS or DTAB [19], and has been rationalized as being due to the larger size of the cationic headgroups on the surface of the micelle [37].

\subsection{Critical concentration evaluation by fluorescence}

We did also perform fluorescence titration experiments for one of the studied systems, namely $\operatorname{dex} \mathrm{C}_{16}-5 \%$ $\left(C=0.13 \mathrm{~g} \mathrm{dL}^{-1}\right)$, to try to determine the critical concentrations by another technique. Aliquots of concentrated SDS solution

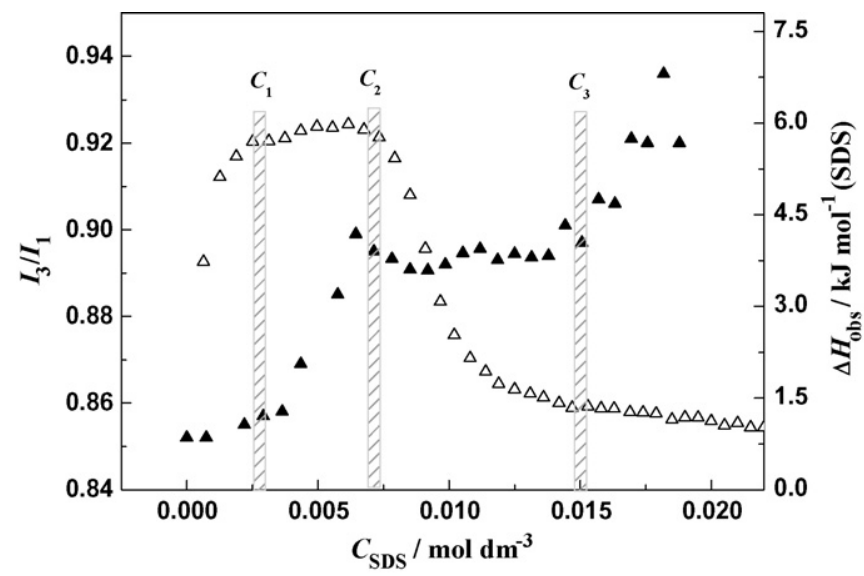

Fig. 5. Comparison between fluorescence $(\boldsymbol{\Delta})$ and ITC $(\triangle)$ results for titration of SDS $\left(0.2 \mathrm{~mol} \mathrm{dm}^{-3}\right)$ into dexC $16-5 \%\left(C=0.13 \mathrm{~g} \mathrm{dL}^{-1}\right)$

were added to polymer solution, with the same concentrations and volumes as in the calorimetric titration experiment. The obtained values of $I_{3} / I_{1}$ as a function of SDS concentration can be seen in Fig. 5, where they are compared with the corresponding observed enthalpy curve. Despite the observed scattering, the derived critical concentrations are in close agreement with the ones observed by calorimetry- a first break is observed at $\sim 3.1 \times 10^{-3} \mathrm{~mol} \mathrm{dm}^{-3}$ corresponding to $C_{1}$, a second break is observed at $\sim 7 \times 10^{-3} \mathrm{~mol} \mathrm{dm}^{-3}$, corresponding to $C_{2}$, and finally a third break is detected at $\sim 15 \times 10^{-3} \mathrm{~mol} \mathrm{dm}^{-3}$, which in our calorimetric titration curves corresponds to the concentration after which we only observe the dilution of micelles $\left(C_{3}\right)$.

From Fig. 5, the following succession of events can be envisaged: below $C_{1}$, binding of SDS to polymer takes place but there is yet no significant change in polymer hydrophobic microdomain polarity $\left(I_{3} / I_{1}\right.$ changes are small). Between $C_{1}$ and $C_{2}$ the binding of surfactant to hydrophobic microdomain gives rise to rich-SDS mixed micelles which are less polar than the hydrophobic microdomains of pure polymer $\left(I_{3} / I_{1}\right.$ increases). This concentration $C_{2}$ should be a critical aggregation concentration of surfactant in the presence of polymer, as between $C_{2}$ and $C_{3}$ there is no change in the polarity of the aggregates present in the system $\left(I_{3} / I_{1}\right.$ about constant). After the third break point $\left(C_{3}\right)$ the fluorescence curve indicates the formation of pure SDS micelles $-I_{3} / I_{1}$ increases again, indicating a change in aggregate polarity which is not accompanied by a change in thermodynamic properties in this region, as the calorimetric curve coincides with the one for dilution of pure SDS into water. Taking into account the difference between the two methods, we consider this agreement very rewarding.

\subsection{Dependence of aggregation behaviour of polymer/surfactant systems on the molar ratio $\left(R=n_{\mathrm{S}} / n_{\text {side group }}\right)$}

As mentioned above, the aggregation behaviour of mixed systems depends not only on the surfactant concentration but also on the polymer's hydrophobic side group concentration. 

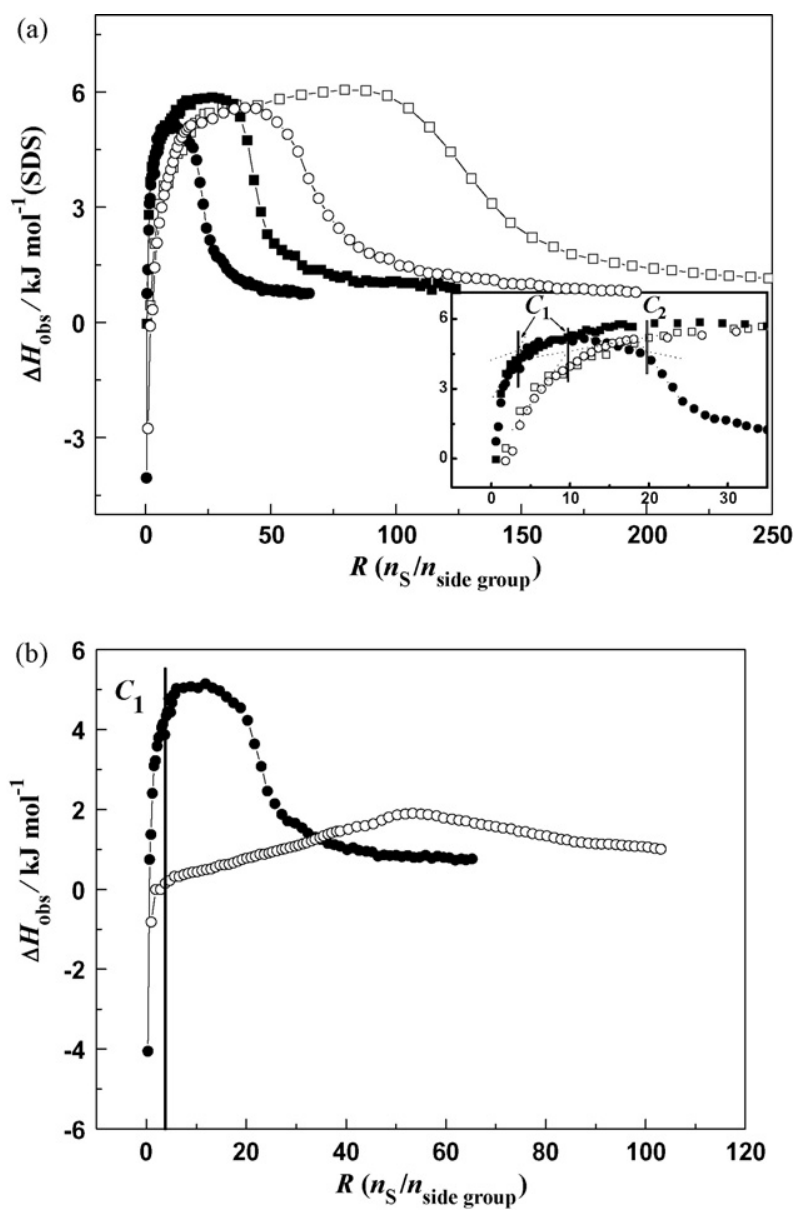

Fig. 6. Plots of observed enthalpies as function of the molar ratio of surfactant to hydrophobic side group, $R\left(n_{\mathrm{s}} / n_{\text {side group }}\right)$. (a) Empty symbols are used for dexC $\mathrm{C}_{16}-1 \% / \mathrm{SDS}$, and filled symbols for $\mathrm{dexC}_{16}-3 \% / \mathrm{SDS}$ : polymer concentrations are $0.13 \mathrm{~g} \mathrm{dL}^{-1}$ ( $\square$ ) and $0.25 \mathrm{~g} \mathrm{dL}^{-1}(\bigcirc)$ ). Insert: enlargement of the low ratio region. (b) Comparison between $\operatorname{dexC}_{16^{-}} 3 \% / \mathrm{SDS}(\bullet)$ and $\mathrm{dexC}_{16^{-}}$ $3 \% / \mathrm{DTAC}(\bigcirc)$ for a polymer concentration of $0.25 \mathrm{~g} \mathrm{dL}^{-1}$.

Moreover the significance of the molar ratio of surfactant to hydrophobic side group ( $\left.R=n_{\mathrm{s}} / n_{\text {side group }}\right)$ must be emphasized, since the nature of the mixed aggregates may vary strongly with this ratio [38]. Therefore, we did plot the observed enthalpy

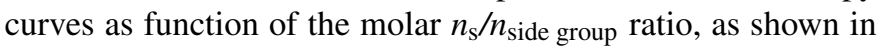
Fig. 6. By plotting $\Delta H_{\text {obs }}$ vs. $R$ a reasonable comparison can be made between different mixed systems, and hence extract the common factors as well as the differences in the various association processes.

The molar ratios at critical concentrations related to the formation of mixed micelles $\left(C_{1}\right)$ and the onset of the surfactant aggregation in the presence of polymer $\left(C_{2}\right)$ can all be clearly identified, as illustrated in Fig. 6a. It is found that the molar ratios at $C_{1}$ are almost independent of polymer concentration, but depend on the $\mathrm{DS}_{\mathrm{C} 16}$ (see the insert in Fig. 6a, $R=\sim 4$ for $\operatorname{dexC}_{16}-3 \%$ and $R=\sim 10$ for $\operatorname{dexC}_{16}-1 \%$ ). Further it is seen in Fig. $6 \mathrm{~b}$ that the ratios at $C_{1}$ do not depend on surfactant head-group. This suggests that the polymer molecular structure has an important effect on polymer aggregation behaviour. At variance, the molar ratios at $C_{2}$ are very high and depend to a large extent on polymer concentration and $\mathrm{DS}_{\mathrm{C} 16}$
(Fig. 6a). The higher the hydrophobic side group concentrations the more surfactant molecules are needed for saturating polymer alkyl chains. Clearly in this surfactant-rich region, the aggregation behaviour is more and more controlled by the surfactant behaviour - for the two systems with different surfactants (SDS and DTAC) the molar ratios at $C_{2}$ are very different, reflecting the aggregation behaviour of the respective pure surfactant (Fig. 6b).

This is in line with Piculell et al. [38], where it is shown that the size of the aggregate may vary strongly with the ratio, $n_{\mathrm{s}} / n_{\text {side group }}$. When the ratio is low in the mixed aggregates, the aggregates are dominated by the polymer characteristics, and the aggregates may be similar to the pure HMP aggregates in the absence of surfactant. Conversely, the aggregates may be similar to those of the pure surfactant at very high surfactant concentrations. At intermediate ratios, mixed aggregates are formed, with varying properties, from mostly polymer-like to mostly surfactant-like.

\subsection{Dilution profiles of binary mixtures of $\left(\operatorname{dex} C_{16}+S D S\right)$ into water}

The studied polymers can be considered as similar to a polymeric surfactant connected by hydrophilic spacers at the level of the head groups (Fig. 1). As pointed by Piculell et al. studies in their laboratory have shown that several features of $\mathrm{HMP} /$ surfactant mixtures may be rationalised if one considers the close analogy between HMP-surfactant association and the mixed micellization of surfactants [32]. Therefore by analogy with calorimetric studies on binary mixture of surfactants [39], we did carry out ITC measurements on binary mixtures of SDS and dex $\mathrm{C}_{16}$ with three different $\mathrm{DS}_{\mathrm{C} 16}$, in order to get a deeper understanding of the interaction behaviour at low polymer concentration. Fig. 7 shows the observed enthalpy curves obtained for the titration of these binary aqueous mixtures $\left(0.2 \mathrm{~mol} \mathrm{dm}^{-3}\right.$ $\mathrm{SDS}+1.0 \mathrm{~g} \mathrm{dL}^{-1}$ polymer) into water. The three studied mix-

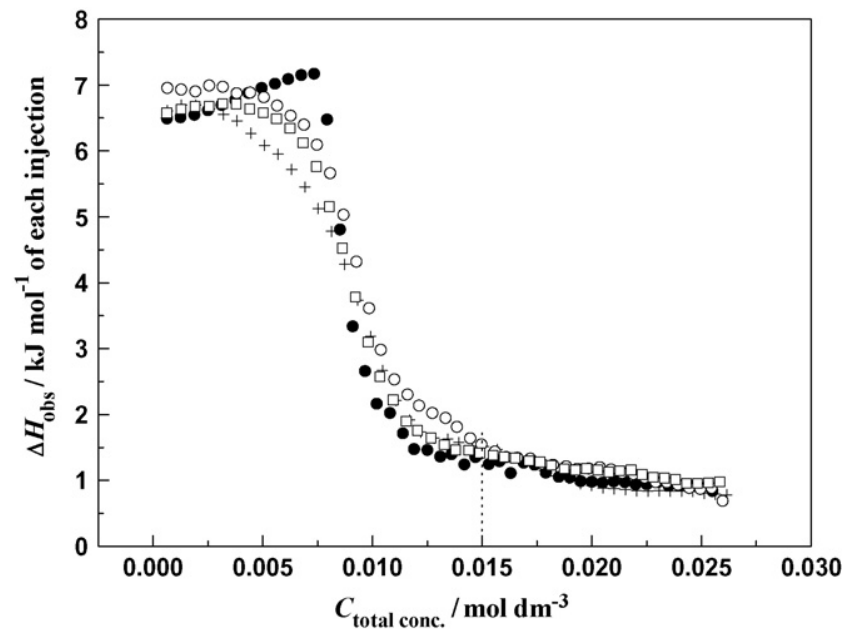

Fig. 7. Calorimetric titration curves for the dilution of mixtures of concentrated $\operatorname{SDS}\left(0.2 \mathrm{~mol} \mathrm{dm}^{-3}\right)+\operatorname{dexC}_{16}\left(1.0 \mathrm{~g} \mathrm{dL}^{-1}\right)$ into water for polymers with different degrees of substitution, as well as titration of pure SDS into water at $308.15 \mathrm{~K}$.

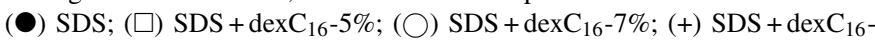
$10 \%$. 
tures in the syringe have different molar ratios of SDS to alkyl side chains of the polymer (SDS:alkyl side chain), due to different $\mathrm{DS}_{\mathrm{C} 16}$ : for $\mathrm{SDS}+\operatorname{dex}_{16}-5 \%-74: 1$; for $\mathrm{SDS}+\operatorname{dexC}_{16}-7 \%$ $-55: 1$ and for SDS $+\operatorname{dexC}_{16}-10 \%-40: 1$.

It should be stressed that $\operatorname{dex}_{16}$ cannot be dissolved in water at concentrations higher than $0.25 \mathrm{~g} \mathrm{dL}^{-1}$, irrespectively of $\mathrm{DS}_{\mathrm{C} 16}$, but all polymers can be easily solubilised in SDS micelle solution. This must be either due to the insertion of the pendant alkyl chains of the polymer into the hydrophobic core of SDS micelles, forming mixed aggregates, or to the absorption of SDS micelles on the surface of the polymer to form a necklacelike structure $[33,40]$. As described above, the aggregates may be similar to those of the pure surfactant. Whatever the detailed mechanism is, there is an increase in HMP solubility, showing again the existence of an interaction between the polymer and the surfactant.

The dilution process for the polymer/surfactant mixtures in water is endothermic. The curves do not diverge much from pure SDS dilution into water and the transition is not so sharp. Note that the polymer concentration in the calorimetric vessel becomes very low (about $C_{\text {polymer }}=0.003 \mathrm{~g} \mathrm{dL}^{-1}-0.04 \mathrm{~g} \mathrm{dL}^{-1}$ when $\left.C_{\mathrm{SDS}}<\mathrm{cmc}\right)$, and therefore what we observe reflects mainly the SDS aggregation behaviour. When the total hydrophobic chain concentration $\left(C_{\mathrm{SDS}}+C_{\text {side group }}\right)$ is about $(5-10) \times 10^{-3} \mathrm{~mol} \mathrm{dm}^{-3}$, the aggregation of surfactant takes place in the presence of polymer. In this concentration range, the observed decrease in the slope of the polymer/SDS curve as compared to pure SDS is an indication of less cooperativity of the assembling process. When the final concentration is about $15 \times 10^{-3} \mathrm{~mol} \mathrm{dm}^{-3}$, the observed enthalpy curves joins the SDS dilution curve, and free SDS micelles form.

\section{Conclusions}

(i) Steady-state fluorescence measurements have been made on a series of newly synthesized hydrophobically modified polymers $\left(\mathrm{dex}_{16}\right)$ with different degrees of substitution $\left(\mathrm{DS}_{\mathrm{C} 16}\right)$. The results show that these polymers can selfassemble in water, forming micelle-like aggregates through association of the hydrophobic pendant groups.

(ii) The cmc values of $\operatorname{dex}_{16}$ were obtained from fluorescence measurements. When expressed as a function of side group concentration, they are of the same order of magnitude as the cmc values of single chain non-ionic surfactants with the same number of carbon atoms on the alkyl chain. This stresses that the concentration of hydrophobic side group is the most important parameter when discussing HMP selfassembling.

(iii) ITC results show that these HMPs can associate with ionic surfactants (SDS and DTAC) due to hydrophobic interaction between surfactant alkyl chains and the polymer pendant groups. The obtained critical concentrations and the aggregation behaviour were confirmed by fluorescence measurements. By combining the observed enthalpies with the enthalpy of micellization of pure surfactant in water we did derive the interaction enthalpies, $\Delta H_{\text {int }}$. The obtained values were related to the suggested mechanism of inter- action: (a) at low SDS concentration, the SDS monomers are incorporated into the DexC16 aggregates until they start to disintegrate with consequently rehydration of the polymer chains; (b) in the middle concentration range there is a complicated self-assembling process involving different structural changes; (c) at the highest SDS concentrations dexC16 monomers are decorated with SDS micelles until saturation occurs. The enthalpies of aggregation can be derived from the observed enthalpy curves of the mixed systems. The values of $\Delta H_{\text {agg }}$ for all studied systems are negative, suggesting that the process is either enthalpydriven or enthalpy- and entropy-driven.

(iv) The significance of the molar ratio of surfactant to hydrophobic side group ( $\left.R=n_{\mathrm{S}} / n_{\text {side group }}\right)$ was emphasized, as the nature of the mixed aggregates may vary strongly with this ratio. Therefore, by plotting the observed enthalpy curves as function of the molar $n_{\mathrm{S}} / n_{\text {side group ratio a com- }}$ parison was made between different mixed systems. It was found that the molar ratios at $C_{1}$ are almost independent of polymer concentration, but depend on the $\mathrm{DS}_{\mathrm{C} 16}$. Further the ratios at $C_{1}$ do not depend on surfactant head-group. At variance, the molar ratios at $C_{2}$ are very high and depend to a large extent on polymer concentration and $\mathrm{DS}_{\mathrm{C} 16}$.

(v) ITC dilution measurements were performed on binary mixtures of SDS and $\operatorname{dexC}_{16}$ for three different degrees of substitution. It is worth noting that these polymers cannot be dissolved in water at concentrations higher than $0.25 \mathrm{~g} \mathrm{dL}^{-1}$, irrespectively of $\mathrm{DS}_{\mathrm{C} 16}$, but all polymers can be easily solubilised in SDS micelle solution. This increase in HMP solubility has a great potential in some fields of application.

\section{Acknowledgments}

Thanks are due to FCT for financial support to CIQ(UP), Unidade de Investigação 81, and for Post-Doc grant to G.B (SFRH/BPD/5668/2001) and a Ph.D. grant to C.G. (SFRH/22242/2005).

\section{References}

[1] L. Karlson, K. Thuresson, B. Lindman, Langmuir 18 (2002) 9028-9034.

[2] K. Akiyoshi, E.-C. Kang, S. Kurumada, J. Sunamoto, T. Principi, F.M. Winnik, Macromolecules 33 (2000) 3244-3249.

[3] J. Seixas de Melo, T. Costa, M.D.G. Miguel, B. Lindman, K. Schillen, J. Phys. Chem. B 107 (2003) 12605-12621.

[4] K. Horiuchi, Y. Rharbi, J.G. Spiro, A. Yekta, M.A. Winnik, R.D. Jenkins, D.R. Bassett, Langmuir 15 (1999) 1644-1650.

[5] V. Wintgens, C. Amiel, Langmuir 21 (2005) 11455-11461.

[6] K.C. Tam, R.D. Jenkins, M.A. Winnik, D.R. Bassett, Macromolecules 31 (1998) 4149-4159.

[7] M. Nichifor, A. Lopes, A. Carpov, E. Melo, Macromolecules 32 (1999) 7078-7085.

[8] X.-X. Zhu, M. Nichifor, Acc. Chem. Res. 35 (2002) 539-546.

[9] S. Daoud-Mahammed, C. Ringard-Lefebvre, N. Razzouq, V. Rosilio, B. Gillet, P. Couvreur, C. Amiel, R. Gref, J. Colloid Interface Sci. 307 (2007) 83-93.

[10] I. Couillet, T. Hughes, G. Maitland, F. Candau, Macromolecules 38 (2005) 5271-5282.

[11] K. Miyazawa, F.M. Winnik, J. Phys. Chem. B 107 (2003) 10677-10682. 
[12] H. Tan, K.C. Tam, R.D. Jenkins, Langmuir 16 (2000) 5600-5606.

[13] S. Nilsson, K. Thuresson, P. Hansson, B. Lindman, J. Phys. Chem. B 102 (1998) 7099-7105.

[14] S. Nilsson, K. Thuresson, B. Lindman, B. Nystrom, Macromolecules 33 (2000) 9641-9649.

[15] S. Panmai, R.K. Prud'homme, D.G. Peiffer, S. Jockusch, N.J. Turro, Langmuir 18 (2002) 3860-3864.

[16] R.J. English, J.H. Laurer, R.J. Spontak, S.A. Khan, Ind. Eng. Chem. Res. 41 (2002) 6425-6435.

[17] O. Rosen, J. Sjostrom, L. Piculell, Langmuir 14 (1998) 5795-5801.

[18] R.A. Lauten, A.-L. Kjoniksen, B. Nystrom, Langmuir 17 (2001) 924-930.

[19] G. Bai, Y. Wang, H. Yan, R.K. Thomas, J.C.T. Kwak, J. Phys. Chem. B 106 (2002) 2153-2159.

[20] G. Olofsson, G. Wang, Pure Appl. Chem. 3 (1994) 527-532.

[21] D.M. Bloor, J.F. Holzwarth, E. Wyn-Jones, Langmuir 11 (1995) 2312-2313.

[22] G. Wang, Ph.D. dissertation, Lund University, 1997.

[23] Y. Wang, B. Han, H. Yan, J.C.T. Kwak, Langmuir 13 (1997) 3119-3123.

[24] R.C. Silva, G. Olofsson, K. Schillén, W. Loh, J. Phys. Chem. B 106 (2002) 1239-1246.

[25] S. Dai, K.C. Tam, J. Phys. Chem. B 105 (2001) 10759-10763.

[26] W.P. Seng, K.C. Tam, R.D. Jenkins, D.R. Bassett, Macromolecules 33 (2000) 1727-1733.

[27] H. Bu, A.L. Kjøniksen, A. Elgsaeter, B. Nyström, Colloids Surf. A 278 (2006) 166-174.
[28] C. Gonçalves, J.A. Martins, F.M. Gama, Biomacromolecules 8 (2007) 392-398.

[29] G. Bai, L.M.N.B.F. Santos, M. Nichifor, A. Lopes, M. Bastos, J. Phys. Chem. B 108 (2004) 405-413.

[30] M. Nichifor, S. Lopes, M. Bastos, A. Lopes, J. Phys. Chem. B 108 (2004) 16463-16472.

[31] G. Bai, M. Nichifor, A. Lopes, M. Bastos, J. Phys. Chem. B 109 (2005) 21681-21689.

[32] L. Piculell, F. Guillemet, K. Thuresson, V. Shubin, O. Ericsson, Adv. Colloid Interface Sci. 63 (1996) 1-21.

[33] B. Jönsson, B. Lindman, K. Holmberg, B. Kronberg, Surfactants and Polymers in Aqueous Solution, John Wiley \&Sons Ltd., 1998, pp. 38.

[34] D. Balasubramanian, B. Raman, C. Sivakama Sundari, J. Am. Chem. Soc. 115 (1993) 74-77.

[35] R. Cardoso da Silva, G. Olofsson, K. Schillén, W. Loh, J. Phys. Chem. B 106 (2002) 1239-1246.

[36] S. Couderc-Azouani, J. Sidhu, T. Thurn, R. Xu, D.M. Bloor, J. Penfold, J.F. Holzwarth, E. Wyn-Jones, Langmuir 21 (2005) 10197-10208.

[37] J.C. Brackmant, J.B.F.N. Engberts, Chem. Soc. Rev. 22 (1993) 85-92.

[38] L. Piculell, K. Thuresson, B. Lindman, Polym. Adv. Technol. 12 (2001) 44-69.

[39] G.B. Ray, I. Chakraborty, S. Ghosh, S.P. Moulik, R. Palepu, Langmuir 21 (2005) 10958-10967.

[40] Z. Gao, R.E. Wasylishen, J.C.T. Kwak, J. Phys. Chem. 95 (1991) 462-467. 